\title{
SEXUAL DIM ORPHISM IN THE LOCATION OF MANDIBULAR FORAMEN USING DISCRIMINATIVE FUNCTION ANALYSIS TEST
}

\section{Shiny Vinila B H *1, Eshwar T 2, John Jims V 2 , Sri Kavya T 2 .}

${ }^{* 1}$ Senior lecturer, Department of Anatomy, Panineeya M ahavidyalaya Institute of Dental Sciences and Research Center, Hyderabad, India.

${ }^{2} 3^{\text {rd }}$ Year BDS student, Panineeya M ahavidyalaya Institute of Dental Sciences and Research Center, Hyderabad, India.

\section{ABSTRACT}

Aim: To determine the sexual dimorphism of mandible based on the location of the mandibular foramen using discriminative function analysis test.

Materials and M ethods: This study was carried out on 70 mandibles ( 43 male, 27 female) which were collected from the department of Anatomy. A total of 140 mandibular foramina (70 left and 70 right) were included in the study. The distance from the center of mandibular foramen to various anatomical land marks were measured. From the center of mandibular foramen to the anterior border of ramus of mandible, From the center of mandibular foramen to the posterior border of ramus of mandible, From the center of mandibular foramen to the inferior borders of ramus of the mandible and From the center of mandibular foramen to the the mandibular notch were measured using digital vernier calipers and data was analyzed using spss $16^{\text {th }}$ version.

Results: The results showed that there is a significant difference between the distance from the center of the mandibular foramen to the anterior border and mandibular notch. Stepwise and direct discriminative analysis shows sexual dimorphism with $90 \%$ accuracy bearing Wilkin's lambda and Eigen values as 0.475 and 1.104 respectively.

Conclusion: In the present study the sex of the mandible was determined with $90 \%$ accuracy by using the distance from the center of the mandibular foramen to the borders of ramus of the mandibles.

KEY WORDS: M andible, Sex determination, Mandibular foramen, Ramus of mandible, Discriminative functional analysis.

Address for Correspondence: B H Shiny Vinila, Senior Lecturer, Department of Anatomy, Panineeya Mahavidyalaya Institute of Dental sciences and Research Center, Kamalanagar, Chaitanyapuri, Dilsukhnagar, Hyderabad, 500060 Contact number: 7731933238 E-M ail: bhvineela@gmail.com

\begin{tabular}{|l|l|}
\hline \multicolumn{3}{|c|}{ Access this Article online } \\
\hline Quick Response code & Web site: International Journal of Anatomy and Research \\
ISSN 2321-4287 \\
www.ijmhr.org/ijar.htm
\end{tabular}

\section{INTRODUCTION}

Identification of a human is based on three important factors in the forensic science; they are age, sex and stature. Bones are the important tool for it and among human bones the pelvis and the skull are the most reliable source for sex determination [1].
However, a perfect pelvis is not present in most circumstances, and a mandible of the skull becomes an important source for sex confirmation. As a component of the skull, the mandible may be considered as second most sexually dimorphic bone. The skull is the second most sexually dimorphic region of the human skeleton apart 
from pelvis. As a component of the skull, the mandible may also be considered sexually dimorphic [2]. In mass disasters it can retain its shape better than other and commonly resist post mortem damages and form an important source of information about sexual dimorphism [3].

The mandible is the largest and strongest bone in the face with a horizontally curved body that is convex forwards with two broad rami, which ascend from the posterior end of the body. The rami bears the coronoid and condyloid processes. The mandibular foramen (M F) is located above the center on the medial surface of the ramus of the mandible. The mandibular canal starts at the M F and descends obliquely forward in the ramus and later in the body of mandible containing the inferior alveolar neurovascular bundle [4].

In general male mandibles are large, prominent muscular attachment sites and slightly more robust than the female mandibles. The outer appearance of male mandibles is usually irregular, whereas that of females is likely to be even. Several non-metric traits of the mandible have been associated with sex. This contradiction may be caused by relative development of the musculoskeletal system in different sexes. Therefore, mandibular size and shape is affected by variable lifestyles, dietary behaviour, and also racial groups [2].

So the study was carried out to assess the sexual dimorphism in mandible. The sex predetermined on the basis of the skull was taken as standard and accordingly 27 female and 43 male mandibles were taken in the present study.

\section{MATERIALS AND METHODS}

This study was carried out on 70 mandibles (43 male, 27 female) which were collected from the department of Anatomy. Total of 140 mandibular foramen (70 left and 70 right) were included in the study. The sex of the mandible was determined according to the following criteria: Gonial eversion marked in males/absent in females; Chin square in males/rounded or pointed in females; Male mandible robust, larger, broader/ female slender, smaller; In males lateral aspect of angle shows rough appearance. In females, the lateral aspect of the angle is comparatively smooth.

Fig.1: Showing the distance from the center of mandibular foramen to the anterior border of ramus of mandible.

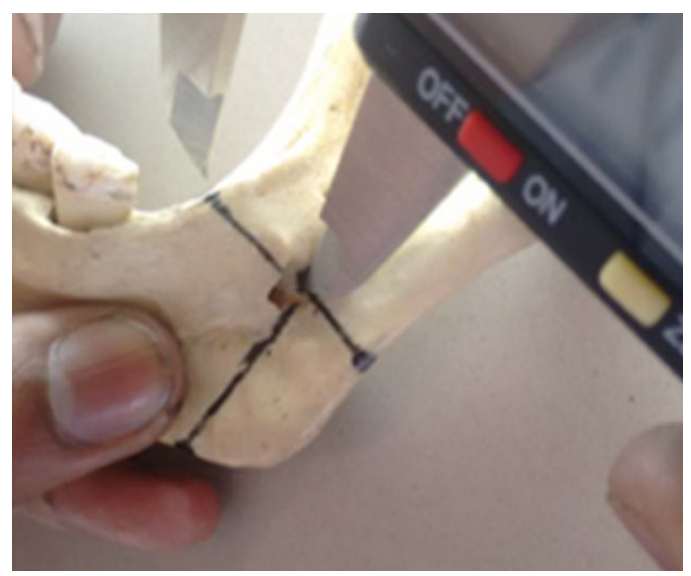

Fig. 2: Showing the distance from the center of mandibular foramen to the posterior border of ramus of mandible.

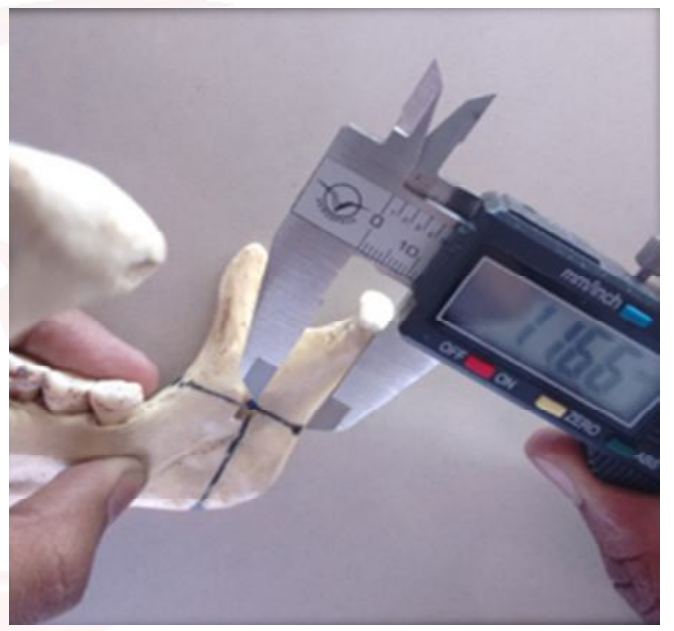

Fig. 3: Showing the distance from the center of mandibular foramen to the inferior borders of ramus of the mandible.

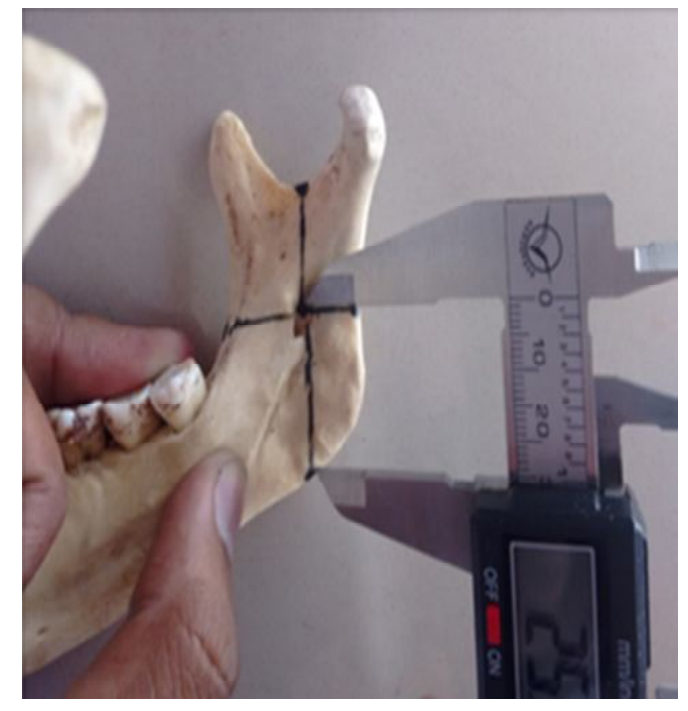

The following metric parameters were used to locate the mandibular foramen. The distance from the center of mandibular foramen to various anatomical land marks were measured. 
From the center of mandibular foramen to the anterior border of ramus of mandible (Figure 1), From the center of mandibular foramen to the posterior border of ramus of mandible (Figure 2 ), From the center of mandibular foramen to the inferior borders of ramus of the mandible (Figure 3 ) and From the center of mandibular foramen to the the mandibular notch (Figure 4) were measured using digital vernier calipers and data was recorded.

Fig. 4: Showing the distance from the center of mandibular foramen to the mandibular notch.

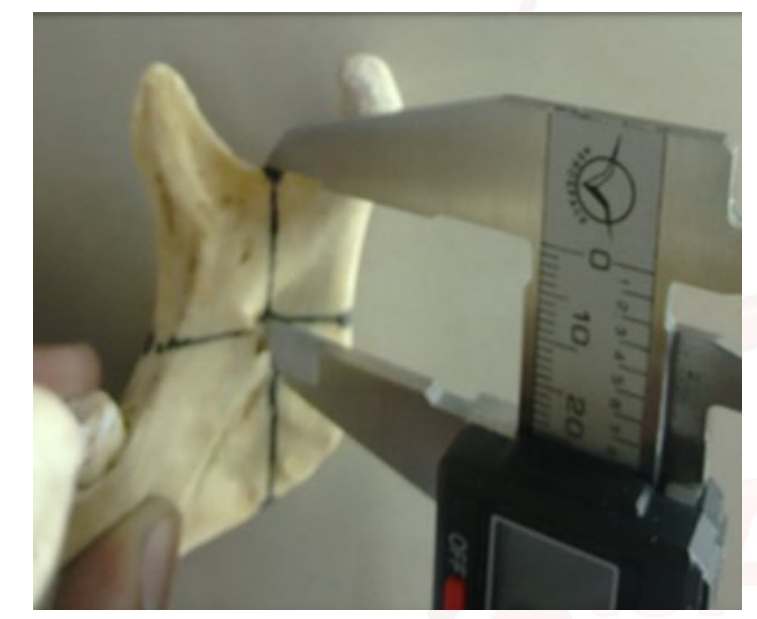

RESULTS

Table 1: Showing the Gender variation in the location of the mandibular foramen.

\begin{tabular}{|c|c|c|c|c|}
\hline Parameter & Gender & Range & Mean & SD \\
\hline \multirow{2}{*}{ MF to M N } & Female & $13.3-25.3$ & 20.1 & 2.49 \\
\cline { 2 - 5 } & Male & $11.1-26.7$ & 19.9 & 3.06 \\
\hline \multirow{2}{*}{ MF to PB } & Female & $10.1-21.3$ & 13.4 & 1.99 \\
\cline { 2 - 5 } & Male & $10.7-20.5$ & 14.3 & 1.8 \\
\hline \multirow{2}{*}{ MF to IB } & Female & $14.7-34.0$ & 25.5 & 3.69 \\
\cline { 2 - 5 } & Male & $21.1-39.3$ & 28.2 & 3.84 \\
\hline \multirow{2}{*}{ MF to AB } & Female & $10.73-19.7$ & 15.56 & 16.27 \\
\cline { 2 - 5 } & Male & $13.23-23.1$ & 17.97 & 17.41 \\
\hline
\end{tabular}

Fig. 5: Showing the gender variation in bar diagram.

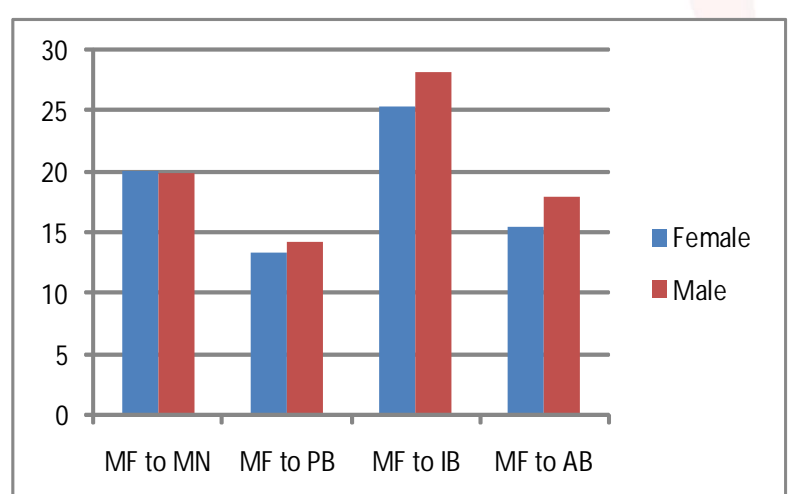

The average distance between the mandibular foramen to mandibular notch, the posterior border of ramus, the inferior border of ramus and the anterior border of ramus in male and female mandibles were recorded in table 1. Significant difference was observed between male and female mandibles (Figure 5)

The data was processed for functional discriminative analysis by using SPSS software (Version 16). Discriminative functional analysis was developed for all the variables and presented in table 2. The variable distance from the mandibular-foramen to anterior border was found to be most dimorphic for sex determination followed by distance between mandibular foramen to superior and inferior borders (Table 2,3,4). The eigen value was found to be 1.104 and the Wilks' Lambda was found to be 0.475 which variable contributes significance in discriminat function. In the present study the mandibles were classified into male and female groups with $90.0 \%$ of accuracy (Table 5).

Table 2: Variables in the analysis.

\begin{tabular}{|c|c|c|c|c|}
\hline STEP & Tolerance & F to Remove & $\begin{array}{c}\text { Min D } \\
\text { Squared }\end{array}$ & $\begin{array}{c}\text { Between } \\
\text { Groups }\end{array}$ \\
\hline 1 MF -AB & 1 & 35.644 & & \\
\hline 2 MF- AB & 0.994 & 21.017 & 1.842 & .00 and 1.00 \\
MF- MN & 0.994 & 16.697 & 2.149 & .00 and 1.00 \\
\hline 3 MF- AB & 0.992 & 19.502 & 2.56 & .00 and 1.00 \\
MF- MN & 0.993 & 15.189 & 2.913 & .00 and 1.00 \\
MF - IB & 0.997 & 6.942 & 3.706 & .00 and 1.00 \\
\hline
\end{tabular}

Table 3: Eigen values.

\begin{tabular}{|c|c|c|c|c|}
\hline Function & Eigen value & $\begin{array}{c}\% \text { of } \\
\text { variance }\end{array}$ & $\begin{array}{c}\text { Cumulative } \\
\%\end{array}$ & $\begin{array}{c}\text { Canonical } \\
\text { correlation }\end{array}$ \\
\hline 1 & 1.104 & 100 & 100 & 0.724 \\
\hline
\end{tabular}

Table 4: Wilks' Lambda test.

\begin{tabular}{|c|c|c|c|c|}
\hline $\begin{array}{c}\text { Test of } \\
\text { functions }\end{array}$ & $\begin{array}{c}\text { Wilk's } \\
\text { Lambda }\end{array}$ & Chi-square & Df & Sig \\
\hline 1 & 0.475 & 49.474 & 3 & 0 \\
\hline
\end{tabular}

Table 5: Group classification.

\begin{tabular}{|c|c|c|c|c|c|}
\hline \multicolumn{3}{|c|}{ Gender } & \multicolumn{2}{|c|}{$\begin{array}{c}\text { Predicted group } \\
\text { membership }\end{array}$} & \multirow{2}{*}{ Total } \\
\cline { 3 - 5 } \multicolumn{2}{|c|}{} & Female & Male & \\
\hline Original & \multirow{2}{*}{ Count } & F & 22 & 5 & 27 \\
& & M & 2 & 41 & 43 \\
\hline & $\%$ & F & 81.5 & 18.5 & 100 \\
& & M & 4.7 & 95.3 & 100 \\
\hline Cross & \multirow{2}{*}{ Count } & F & 22 & 5 & 27 \\
validated & & M & 3 & 40 & 43 \\
\hline & \multirow{2}{*}{$*$} & F & 81.5 & 18.5 & \multirow{2}{*}{100} \\
\hline
\end{tabular}

$90.0 \%$ of original grouped cases are correctly classified

\section{DISCUSSION}

Many researchers carried out studies on sex determination of mandible based on the 
morphological features of mandible such as robustness of the mandible, ramus flexure, gonial eversion, square shape of chin, etc., but unlike skull, determination of sex from isolated mandible poses problems even for an experienced examiner. Very few studies describing the discriminant function analysis of mandibles, but due to population specificity of the discriminant function, the results obtained in one area cannot be applied to other area [6]. The discriminant function analysis of mandibles on location of the mandibular foramen was not considered in any studies. The present study was focused on determination of sex of the mandible based on the location of the mandibular foramen in south Indian population.

The results of the present study were compared with other studies done on different population groups. Giles et al., studied on mandibles of American whites and blacks with eight variables and discriminated sex with $84 \%$ accuracy, whereas Hanihara et al., had used four variables of mandibles belonging to Japanese population and discriminated the sex by $85 \%$ accuracy $[7,8]$. Dayal et al., studied six mandibular measurements of South African Blacks and noted that average accuracy for sexing varies from 80 to $85 \%$ [9]. In all the above studies location of the mandibular foramen was not considered at all. The present study focused on the location of the mandibular foramen and the results of the present study reported determination of sex of the mandible with $90 \%$ accuracy.

Location of mandibular foramen can be considered in determination of sex when complete mandible in not available for analysis. Most of the other parameters like bicondylar breadth, coronoid breadth and bigonial breadth need complete mandibles. When a piece of ramus of mandible was found in forensic and or anthropological analysis, the sex determination can be done based on the location of the mandibular foramen.

\section{CONCLUSION}

The uniqueness of the craniofacial features is well known and comparison of the Ante mortem and post-mortem skull configurations may contain sufficiently distinctive patterns for personal identification, even in very badly hurt bodies. This study has resulted in development of population specific data for south Indian population. The result of present study is promising, and the studied MF showed, sexual dimorphism with accuracy comparable with other skeleton elements next to cranium and pelvis.

\section{Conflicts of Interests: None}

\section{REFERENCES}

[1]. Rahul Singh, Suniti R. M ishra, Sushobhana, Jigyasa Passey, Pramod Kumar, Shailendra Singh, Priyanka Sinha. Sexual dimorphism in adult human mandible of North Indian origin. Forensic medicine and anatomy research. 2015; 3: 82-88.

[2]. Smrity Gupta. Sexual Dimorphism in Adult Human Mandible of North Indian Origin. Forensic Medicine and Anatomy Research. 2015;3:82-88.

[3]. Giles, E. (1964) Sex Determination by Discriminate Function Analysis of the Mandible. American Journal of Physical Anthropology. 1964;22:129-135.

[4]. Kim, H.J., Lee, H.Y., Chung, I.H., Cha, I.H. and Yi, CK. Mandibular Anatomy Related to Sagittal Split Ramus Osteotomy in Koreans. Yonsei Medical Journal. 1997;38:19-25.

[5]. Beale T], Robinson PD. Infratemporal and pterygopalatine fossae and temporomandibular joint. In: Standring S, Boreley NR, Healy JC, Collins P, Johnson D, Crossman AR, et al. editors. Gray's Anatomy: The Anatomic Basis of Clinical Practice. 40 th ed. UK: Elsevier Churchill Livingstone; 2008:530-3, 543.

[6]. Kanchankumar P. Wankhede, Rajesh V. Bardale, Gunwant R. Chaudhari, and Namdeo Y. Kamdi. Determination of sex by discriminant function analysis of mandibles from a Central Indian population. J Forensic Dent Sci. 2015;7(1):37-43.

[7]. GilesE. Sex determination by discriminant function analysis of the mandible. Am J Phys Anthropol. 1964;22:129-35.

[8]. Hanihara K. Sex diagnosis of Japanese skulls and scapulae by means of discriminant functions. J Anthropol Soc Nippon. 1959;67:191-7.

[9]. Dayal M R, Spocter M A, Bidmos M A. An assessment of sex using the skull of black South Africans by discriminant function analysis. Homo. 2008;59:2092.

How to cite this article: Shiny Vinila B H, Eshwar T, John Jims V, Sri Kavya T. SEXUAL DIMORPHISM IN THE LOCATION OF MANDIBULAR FORAM EN USING DISCRIM INATIVE FUNCTION ANALYSIS TEST. Int J Anat Res 2017;5(2.3):3964-3967. DOI: 10.16965/ ijar.2017.229 